Theory: Insights \& Ideas [Invited Paper]

\title{
The Philosophy and Psychology of Character
}

\author{
Christian B. Miller ${ }^{1}$ \\ [1] Department of Philosophy, Wake Forest University, Winston-Salem, NC, USA.
}

Personality Science, 2021, Vol. 2, Article e6031, https://doi.org/10.5964/ps.6031

Received: 2021-01-30 • Accepted: 2021-04-20 • Published (VoR): 2021-06-21

Handling Editor: John F. Rauthmann, Bielefeld University, Bielefeld, Germany

Reviewing: Round 1 - Frank Martela; Evan Westra. No open reviews are available

Corresponding Author: Christian B. Miller, Box 7332, Wake Forest University, Winston-Salem, NC 27109, USA. Email: millerc@wfu.edu

\begin{abstract}
In this short reflection piece, I outline how I see both philosophy and psychology contributing to the study of character. In addition, I highlight an area where far more collaborative work needs to be done.
\end{abstract}

\section{Keywords}

character, virtue, philosophy, psychology, honesty, character development

\section{Relevance Statement}

There is a great deal of recent work at the intersection of philosophy and psychology. I clarify some of the ways that both fields can contribute to better understanding issues of character and virtue, with the ultimate aim of growing in virtue.

\section{Key Insights}

- Philosophy helps give an account of the virtues and vices.

- Psychology helps discover the degree to which people possess virtue.

- Developing character improvement strategies needs a lot more attention.

As a moral philosopher, I have drawn extensively on work in psychology to inform my own research on character and virtue over the past two decades. Here I will outline, selectively, how I see both philosophy and psychology contributing to the study of 
character, and also highlight an area where far more collaborative work needs to be done.

First, a quick note on "character" and "personality." There is no consensus in either field about how these two concepts are related to each other, but I have argued that character traits are a specific kind of personality trait (Miller, 2014, Chapter 1). For instance, two young children might different in their degree of extraversion, but I wouldn't want to claim that they differ in their characters. One way to spell out the distinction is in terms of responsibility, praise, and blame, with character tied to these notions. Another way is to claim that character traits are subject to normative criteria of assessment ${ }^{1}$, whereas personality traits do not have to be. Our focus here will just be on character traits.

Starting with philosophy, we can note that character traits come in a variety of different types, with the two leading ones being the virtues (honesty, compassion, gratitude, etc.) and the vices (dishonesty, callousness, ingratitude, etc.). There may be other types as well, such as continence, incontinence, and what I have called "mixed" character traits (Miller, 2013, 2014), but we can set these aside.

Philosophers try to make progress by giving a normative account of what virtues and vices are in general, as well as offering accounts of particular character traits. These accounts attempt to specify what is involved at the level of behavior, as well as underlying thoughts, motives, and emotions. There is no one approach to developing such accounts, but in my own case I have proceeded via a form of reflective equilibrium, trying to balance my intuitions about particular cases with different general claims that aim to fit my intuitions (and explain them too), revising the claims and the intuitions as I go in search of coherence.

To illustrate better some of the relevant normative issues, take the virtue of honesty, which has been the focus of my recent work (Miller, 2021). I have tried to specify what counts as honest and dishonest behavior. Do cheating, stealing, breaking promises, and bullshitting, for instance, all count as dishonest? It is also important to try to specify when it is morally appropriate to exhibit honesty and when it is not, such as in the famous Nazi-at-the-door case. Similarly, I have provided an account of what honest motivation looks like, including whether self-interested motivation would ever count as a virtuous motive for an honest person (Miller, 2021).

With these kinds of concerns, empirical research in personality psychology (or any other branch of psychology, for that matter) will be of little help. We can't read off the empirical data whether one should exhibit the virtue of honesty in a given situation. The same goes for whether compassion should outweigh honesty. Similarly, what motivation a person actually has when telling the truth might be discovered on empirical grounds, but not what motivation should count as virtuous.

1) In this context, "normative" means the evaluative and concerns matters of value, obligation, and the like. 
One issue where philosophers have looked to the empirical research closely for guidance, however, concerns the degree to which people tend to actually possess the virtues or vices. This is something I as a philosopher cannot pronounce upon from the proverbial armchair. I need data. But raw data won't help by itself either. That data needs to be checked against normative criteria as to what counts as being an honest or compassionate or just person. Then we can see how people are doing in this area of their character.

To make this more concrete, consider honesty again. On philosophical grounds, we can develop criteria for assessing the degree to which a person is honest. Here is one example that I have defended in my own work (Miller, 2021, which develops many other examples):

(1) A person who is honest, when acting in character, will regularly refrain from cheating in situations where he is a free and willing participant and the relevant rules are fair and appropriate, even if by cheating he is assured of acquiring some benefit for himself.

With a criterion like this, we can then look to the findings of relevant cheating studies and see to what extent participants meet it or not (for my conclusion, see Miller, 2021).

Honesty is a personality trait, an individual difference variable that comes in degrees of more or less. As such, we can try to determine whether a given person is highly honest, moderately honest, or low on honesty. Similarly, we can examine the level of honest behavior exhibited in groups of people.

More controversially, we might also examine whether a given individual or group is honest at all. Here honesty, as with all other virtues and vices, would be treated as a threshold concept. It comes in degrees of more or less, but at some point it would become so weak as to no longer exist in a person's character. Instead the person would be best described as continent, incontinent, mixed, dishonest, or some other character label besides "honest."

Ascribing thresholds to personality traits is not popular in personality psychology, from what I am told. But it is commonplace in the character literature in philosophy. Indeed, for a while there was a very active situationist debate in philosophy led by Gilbert Harman $(1999,2000)$ and John Doris (2002) which claimed that, according to findings in psychology, most people do not possess any moral virtues or vices whatsoever. I have also defended a similar claim in my own work (Miller, 2013, 2014). The disagreement here between philosophers and personality psychologists on thresholds and related issues about how to conceptualize character traits could be a source of interdisciplinary confusion and is worthy of more study in the future. ${ }^{2}$

2) Thanks to a reviewer for stressing this point. 
Leaving aside thresholds, the main point is that philosophy can provide normative criteria for what it is to be a virtuous person. Psychology can help us assess the extent to which most people succeed in living up to those standards. Together they can jointly paint a picture of the size of what I have called the "character gap" between what our character should be like and what it actually is like.

To be sure, this is not the only way in which philosophy and psychology can work together to make discoveries about character. A philosopher might claim that virtue $A$ and virtue $B$ are closely related to each other (say, honesty and courage). Or that a given virtue has components $\mathrm{X}, \mathrm{Y}$, and $\mathrm{Z}$. Or that a vice leads to some downstream psychological effect (say, increased negative affect). Empirical research could then help to assess these claims by seeing whether the elements in question are highly correlated, assuming that we have good measures of each element in the first place. If they are not highly correlated, then the philosophical claim in question could need revision. ${ }^{3}$

To conclude, one area that is badly underexplored and which could benefit from far more collaborative work between philosophy and psychology, is the development and assessment of character improvement strategies aimed at reducing the character gap mentioned above. This is especially true with respect to particular virtues like honesty. While I have noted that there is some preliminary work on what honesty is (Miller, 2021), and a number of studies which assess lying and cheating behavior in particular, almost nothing has been done either to (1) develop new strategies for fostering honesty, or to (2) empirically assess the existing strategies we already have. Nor is honesty an outlier here. The same is true for just about every other virtue.

If we want our work as moral philosophers and personality psychologists to make a significant and tangible difference in the lives of people, here is one area that is ripe for further exploration.

3) I am grateful to a reviewer for this suggestion. 
Funding: Work on this paper was supported by a grant from the John Templeton Foundation for the Honesty Project. The opinions expressed here are those of the author and do not necessarily reflect the views of the Templeton Foundation.

Acknowledgments: The author is grateful to John F. Rauthmann and two reviewers for Personality Science for their helpful comments.

Competing Interests: The author is an editorial board member of Personality Science.

Author Contributions: Christian B. Miller-Idea, conceptualization | Writing | Feedback, revisions | Funding to conduct the work.

Ethics Statement: No ethical issues and/or ethics approvals need to be disclosed.

Related Versions: No other previously published versions of this manuscript exist in part or in whole.

\section{References}

Doris, J. (2002). Lack of character: Personality and moral behavior. Cambridge University Press.

Harman, G. (1999). Moral philosophy meets social psychology: Virtue ethics and the fundamental attribution error. Proceedings of the Aristotelian Society, 99(1), 315-332.

https://doi.org/10.1111/1467-9264.00062

Harman, G. (2000). The nonexistence of character traits. Proceedings of the Aristotelian Society, 100(1), 223-226. https://doi.org/10.1111/j.0066-7372.2003.00013.x

Miller, C. (2013). Moral character: An empirical theory. Oxford University Press.

Miller, C. (2014). Character and moral psychology. Oxford University Press.

Miller, C. (2021). Honesty: The philosophy and psychology of a neglected virtue. Oxford University Press.

\section{eapp}

Personality Science (PS) is an official journal of the European Association of Personality Psychology (EAPP).
(4) leibniz-psychology.org

PsychOpen GOLD is a publishing service by Leibniz Institute for Psychology (ZPID), Germany. 